\title{
Effect of Sea Water and Natural Ageing on Residual Strength of Epoxy Laminates, Reinforced with Glass and Carbon Woven Fabrics
}

\author{
Andrzej Komorek, ${ }^{1}$ Paweł Przybyłek, ${ }^{1}$ and Wojciech Kucharczyk ${ }^{2}$ \\ ${ }^{1}$ Air Force Academy, Faculty of Aviation, 35 Dywizjonu 303 Street, 08-521 Dęblin, Poland \\ ${ }^{2}$ Faculty of Mechanical Engineering, Kazimierz Pułaski University of Technology and Humanities, 54B Krasickiego Street, \\ 26-600 Radom, Poland \\ Correspondence should be addressed to Andrzej Komorek; komman@op.pl
}

Received 14 February 2016; Accepted 29 May 2016

Academic Editor: Carlo Santulli

Copyright ( $(2016$ Andrzej Komorek et al. This is an open access article distributed under the Creative Commons Attribution License, which permits unrestricted use, distribution, and reproduction in any medium, provided the original work is properly cited.

\begin{abstract}
This paper reports the results of the effect of sea water, natural ageing, and cross-impact loading on flexural strength and residual flexural strength of epoxy laminates with glass woven fabrics and hybrid reinforcement with glass and carbon woven fabrics. The tests were conducted on samples with different fibre reinforcement both before and after low energy cross-impact loading. Carbon fabrics decreased residual strength of the composites.
\end{abstract}

\section{Introduction}

Air constructions are devices which often operate in a specific environment. Aircraft interact directly with the natural environment and are therefore exposed to the destructive influence of weather phenomena as well as the factors which shape the phenomena, including the local environmental ones. Construction elements are consequently exposed to corrosion and the process of erosive ageing. This problem particularly refers to components which remain in immediate contact with the elements of the natural environment (parts of fuselage skin, wings, and tail-plane).

In addition, air constructions may be exposed to, for example, mechanical damage caused by low energy impact loading operating perpendicularly to the element surface [1]. Such damage occurs, for instance, during an impact into the aircraft skin by rocks of various sizes and mass, often occurring in the first and second phase of takeoff and also taxiing of aircraft. If some element of the aircraft or a helicopter is manufactured from a multilayered composite (laminate), then the impact damage to such materials may lead to the emergence of phenomena which contribute to faster corrosive ageing of composite material, as well as lowered strength of the impact loaded structure [1]. A characteristic feature of this kind of damage is delaminations which run tangently to the reinforcement and the matrix base cracks. The area of the damage has the shape of a truncated cone whose tip is fixed in the impact point, spreading towards successive reinforcement layers (Figure 1) [2, 3]. After impact loading, the parameter which is relevant due to safety precautions is the remaining material strength (residual strength), which largely depends upon the impact energy (according to [2] low energy damage is caused by the energy below the level of $136 \mathrm{~J}$ or up to $100 \mathrm{~m} / \mathrm{s}$ of the impactor's speed).

The degradation of the matrix base enables penetration of the composite structure by a degrading factor, which facilitates initiation of stress corrosion of the reinforcement fibres as well as accelerating propagation of delaminations to the sizes which may lead to the element destruction due to loss of stability [3].

The degradation resulting from the influence of the natural environment belongs to a group of atmospheric degradations, which denotes an interaction of a number of tightly linked elements at the same time. The degradation 


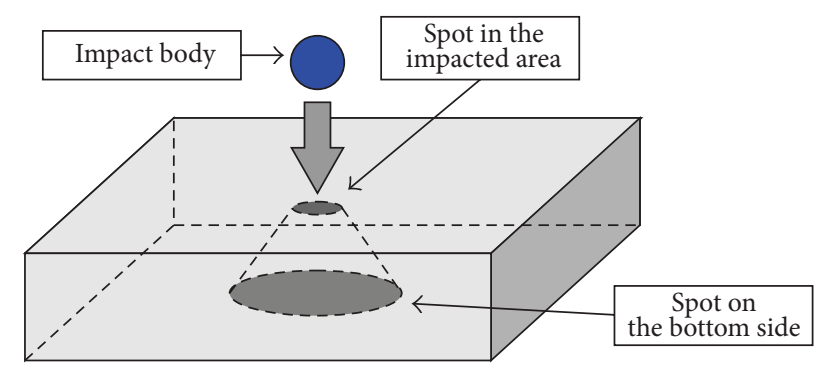

Figure 1: Outline of the damaged area of a composite plate after low energy impact loading [3].

processes mostly embrace photooxidation and thermal oxidation as well as hydrolytic degradation, biodegradation, environmental degradation, and mechanical degradation. The degradation mechanisms taking place in laminate samples which are exposed to the influence of atmospheric factors significantly affect the structure and properties of these multilayered composites [4-7].

The synergic influence of a number of factors causes more extensive damage to the composite structure, as proved by the investigation where a composite is exposed to the influence of sea water. Meanwhile, it is also affected by solar radiation (which generates $\mathrm{UA}-\mathrm{V}$ radiation) and a stream of thermal energy. UV radiation increases the degree of polymer roughness. An uneven surface of the polymer is the place where hydrolytic degradation occurs in favourable conditions. Additionally, a stream of thermal energy which affects the total volume of the composite material causes structural changes of chemical bonds, resulting in their weakening. The consequence of such a complex degradation mechanism is disintegration of bonds as well as weaker composite material. One must stress that the natural ageing method largely depends upon the period of the ageing test $[4,5,7]$.

One of the degrading factors, relevant for the research of ageing processes, is a thermal stream, which is responsible for the occurrence of thermal degradation and which causes changes in the properties of polymer plastic.

Reactions are observed between the polymer and impurities or the components such as fillers or colourants [813]; besides, there are changes in the bonds of the main chain. A strong stream of heat causes the release of free radicals in places of defects in chain structures and on its ends. Simultaneously to the process of bond disintegration, typically a process of hydrolysis occurs due to the presence of traces of water in the polymers. While the polymer is heated with a stream of thermal energy, coming from solar radiation, the molecular mass becomes reduced. Thermal energy may also cause a different type of composite impact loading. Large temperature differences, resulting from natural cycles of temperature curves, may lead to thermal shocks. If the reinforcement is characterised by a different coefficient of linear thermal expansion from the matrix base material, the outcome is stresses which are dangerous to the adhesion between the fibre and the matrix. This phenomenon seems to be particularly hazardous in an environment of large temperature gradients [4, 14-16].

Ultralight aircraft and helicopters which operate over water basins often fly at low altitudes. The character of the flight may expose them to the influence of sea water, whose drops are whirled up by aircraft which also result from the natural behaviour of the sea. The research and its findings presented in the paper aim at specifying the influence of sea water and the natural environment of the earth's atmosphere (ageing) upon the bending strength and the residual strength to bending of epoxide multilayered composites (laminates) with fibre reinforcement, solely with glass woven fabrics or hybrid glass/carbon reinforcement. Hybrid composites are those which have more than one reinforcement in a single matrix or single reinforcement with multiple matrix or multiple reinforcement with multiple matrix. Hybridization can increase the mechanical properties of single fibre polymer composite [17]. This type of materials is often used for the manufacture of airframes of light aircraft or helicopters (e.g., Diamond DA-20, Guimbal Cabri G2) and unmanned aerial vehicles such as the Orbiter-type, which are in service in the Polish military. Due to a real possibility of damaging composite structures by low energy impact loading, we also decided to examine the synergic influence of sea water and ageing, in natural conditions, on samples which had been impact loaded before (assuming that the loading will destroy the matrix layer and allow water to leak in between the layers, etc.). The environmental factor (degrading) was sea water, whereas ageing was conducted in natural conditions (in the season of autumn-spring), in Mideastern part of Poland (Dęblin).

Experiments were carried out on the control samples, which after manufacture were not subjected to environmental and shock loading, and the results of these tests were compared with the results of the samples subjected to the influence of degrading factors (impact, sea water, and environment) acting separately or synergistically. On the basis of the experiments by comparing the results, was determined the influence of the degrading factors on the mechanical properties (bending strength) of the tested composites.

Experimental research was carried out according to the following scenario: making of test plates from composite materials selected for testing, the cutout of samples from composite panels, quality analysis of samples, edge protection against the penetration of samples by degrading factors, subjecting a part of the samples to impact loading simulating a low energy impact loading of solids, subjecting of impact loaded and not loaded samples to influence of sea water and ageing in natural conditions, bending strength determination of the control series samples, determination of bending strength (residual strength) of the samples subjected to impact loading and samples exposed to sea water, and natural aging, discussion, and statistical analysis of the results and formulation of conclusions.

\section{Materials and Methods}

The test samples were made by means of the contact method, in accordance with the PN-EN ISO 604:2003 norms. In the 

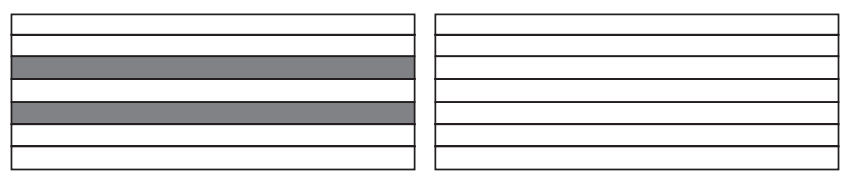

Glass fabric

Carbon fabric

FIgURE 2: Structure of tested laminates.

first phase, laminate control boards, $250 \times 350 \mathrm{~mm}$ in size, were manufactured by the contact method. Each board was used to cut out 30 samples, $80 \times 60 \mathrm{~mm}$ in size, with the average thickness of $3 \mathrm{~mm}$ (the laminate of such thickness is typically used for the aircraft skin). In order to manufacture the composites, glass fabric EE 163P produced by GRM Systems and carbon fabric GG 160P made by G. Angeloni were used, both with plain weave, layered in such a way that it was possible to obtain a symmetrical laminate $(0 / 90)$. The matrix was epoxide resin Epidian 5 manufactured by Z. Ch. Sarzyna. Its characteristic feature is resistance to dampness and corrosion [18] and the highest popular resins (as epoxy resin), formability, and other mechanical properties [19]. The curing process was conducted with Z-1 hardener (triethylenetetramine, TETA), manufactured by Z. Ch. Sarzyna, with 13 mass fractions for 100 resin mass fractions, that is, $13 \mathrm{nS}$. The samples were hardened in the temperature of $21^{\circ} \mathrm{C}$ for at least seven days. During hardening, the control boards were pressed under the pressure of $11.5 \mathrm{hPa}$. The control boards were composed of seven layers of fabrics reinforced by hybrids, and the carbon fabric was placed in the internal layers (Figure 2).

The above-mentioned method was applied in order to manufacture laminates in two material groups:

(1) Epoxide laminates with glass fabric (mass reinforcement degree equals $32.6 \%$ ).

(2) Epoxide hybrid laminates with glass and carbon reinforcement (mass reinforcement share equalling $33.2 \%$, including $23 \%$ of glass fibre and $10.2 \%$ of carbon fibre).

The cutout samples were divided into series, depending upon their application. Each series embraced 5 samples, which were later used for research:

(1) Bend strength evaluation of samples which were not subjected to impact loading:

(i) control samples (5 pieces);

(ii) those after the influence of sea water (36 days, 5 pieces);

(iii) those after atmospheric ageing (99 days, 5 pieces).

(2) Evaluation of residual strength to bending of samples which had been earlier subjected to impact loading, whose energy was equal to $7.1 \mathrm{~J}$ :

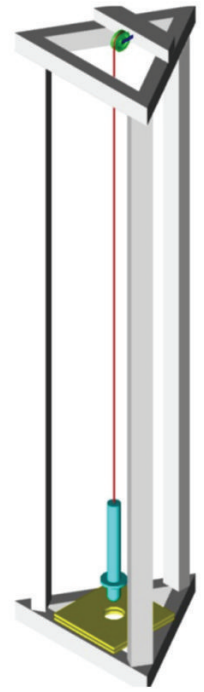

FIgURE 3: Impact hammer, a scheme.

(i) control samples ( 5 pieces);

(ii) those after the influence of sea water (36 days, 5 pieces);

(iii) those after atmospheric ageing (99 days, 5 pieces).

The research into ageing, conducted in the natural environment and in sea water environment, aimed at determining the extent of maintenance work performed in particular maintenance periods on composite elements of aircraft. It was assumed that after approximately 300 flying hours, an aircraft undergoes periodic scheduled maintenance conducted by a specialist unit. Thus, the assumed investigation time $(2,376$ hours) covers eight interservicing periods. Moreover, it was assumed that the synergic influence of sea water and the natural conditions upon the airframe elements in aircraft occurs by approximately $30 \%$ of the total flying hours. The exposure times, selected in such a way, correspond to the real exploitation conditions of an aircraft of approximately 10 years, with an average number of flying hours calculated on the basis of a real number of flying hours of the aircraft in service at the Air Force Academy (Diamond DA-20, Guimbal Cabri G2).

Half of all the specimens $(2 \times 15$ pieces $)$ were exposed to impact loading, whose aim was to simulate damage caused as a consequence of the contact of aircraft composite elements with a foreign object. A conducted impact test exploited an impact hammer, which was designed in the laboratory of the Faculty of Aviation at the Air Force Academy in Dęblin; see Figure 3. The test was conducted in accordance with the PNEN 438-2:2005 norm. A specially selected height and the mass of the impactor enabled obtaining low energy damage. The calculated energy of impact loading equalled 7.1 J.

During the macroscopic observation of impact loaded samples, we observed damage whose character resembled the kind of damage described in the available literature $[2,3]$. In particular, it was possible to observe cracks and crushing of 


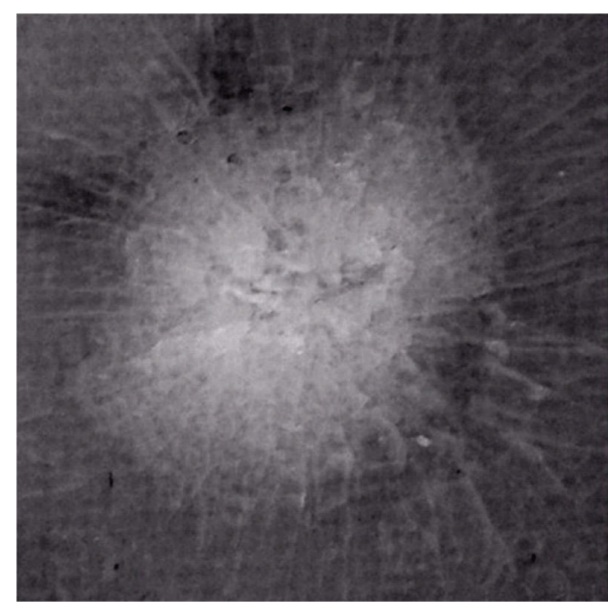

FIGURE 4: Cracks of sample matrix at the place of hitting after impact loading.

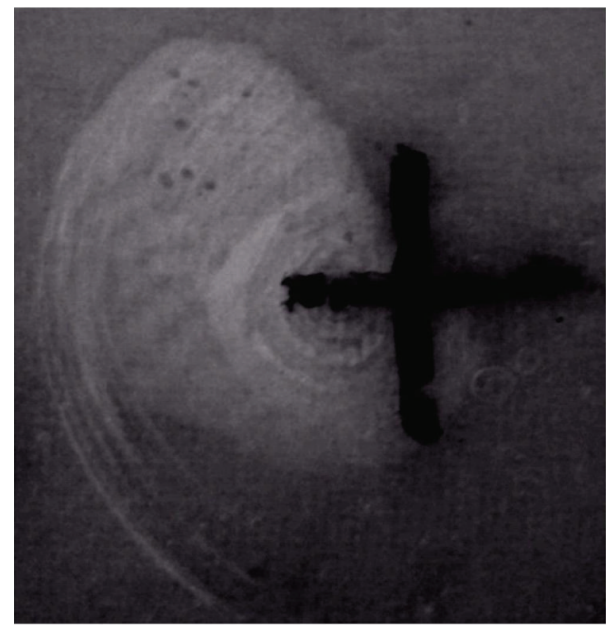

Figure 5: Sample delaminating area at the place of hitting after impact loading.

the matrix as well as extensive areas of delamination, depicted in Figures 4 and 5.

After cutting out the samples from the control boards, the edges of the samples were unprotected; therefore it was easy for the degrading factors to enter the internal structure of the composite, causing its accelerated ageing. In order to avoid this phenomenon, on completion of the tests where the impact hammer was used, the edges of all the sample pieces were protected with epoxide resin Epidian 5, cured by means of Z-1 hardener (13 nS).

During the next stage, we determined the mechanical properties of the manufactured laminate, by examining the sample from the control series $(2 \times 10$ pieces $)$. In order to assess the properties, we used the three-point bending test on a universal test machine ZWICK/ROELL Z100. The distance between the support legs equalled $64 \mathrm{~mm}$. The three-bend test allowed calculating the bend strength $R_{g}$.

The specially selected samples, $2 \times 10$ items, were then subjected to the influence of sea water, with its periodical

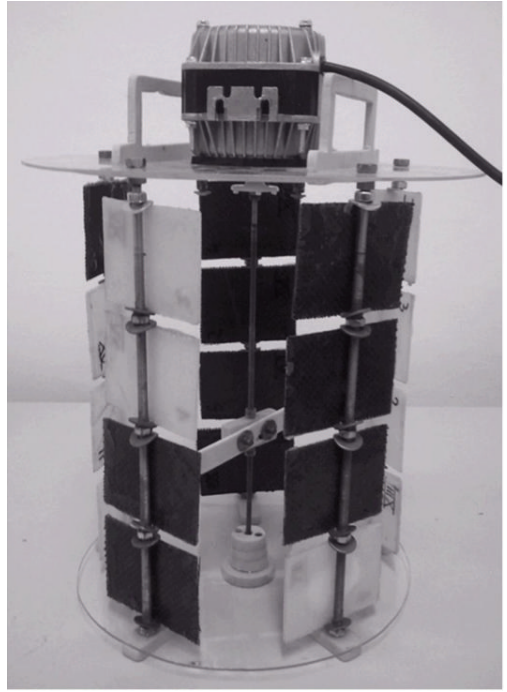

Figure 6: Stand for sea water tests.

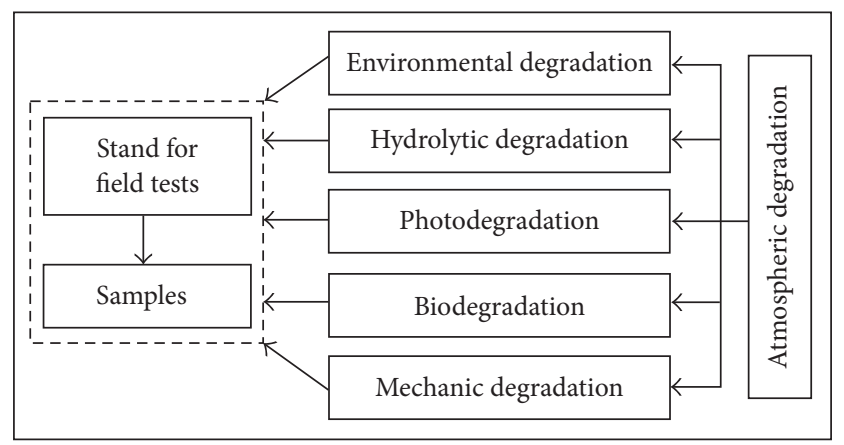

FIGURE 7: Scheme of natural ageing stand.

movement. This type of task was conducted on a specially designed device, depicted in Figure 6.

Based on the adopted assumptions, we decided to carry out the research in conditions which mirror the real exploitation conditions of the aircraft as close as possible. For the sake of the investigation, we used sea water from the Baltic Sea, which is characterised by salinity of 7.8\%o. Deep water resources are characterised by a rise in salinity up to approximately $16 \%$. Moreover, the water from the Baltic Sea waves considerably. The process of eutrophication largely affects the chemical composition of the water.

The specimens were fixed in the machine, symmetrically around the rod, which had a stirrer mounted, in order to whirl the water from time to time. The sea water affected the samples for a period of 864 hours (36 days). The water temperature was equal to $15^{\circ} \mathrm{C}$ during the test. Finally, we inspected the surface of the samples visually in order to detect changes in the structure, colour, and gloss of the material.

In order to determine the influence of the natural atmospheric degradation upon the strength of the epoxide glass composite and the glass-carbon composite, we prepared a stand for field tests. Figure 7 shows a schematic diagram, whereas Figure 8 is a stand for performing tests with the fixed 


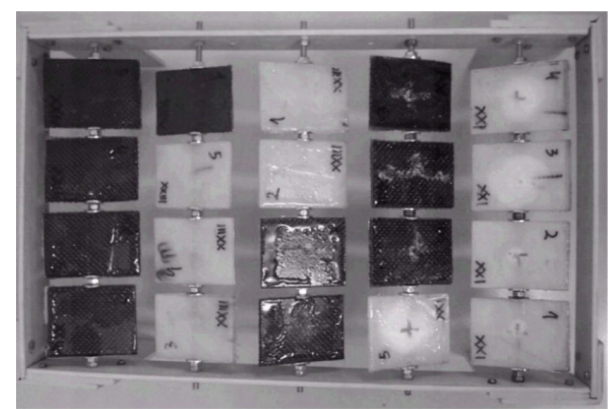

Figure 8: Natural ageing stand with fixed samples.

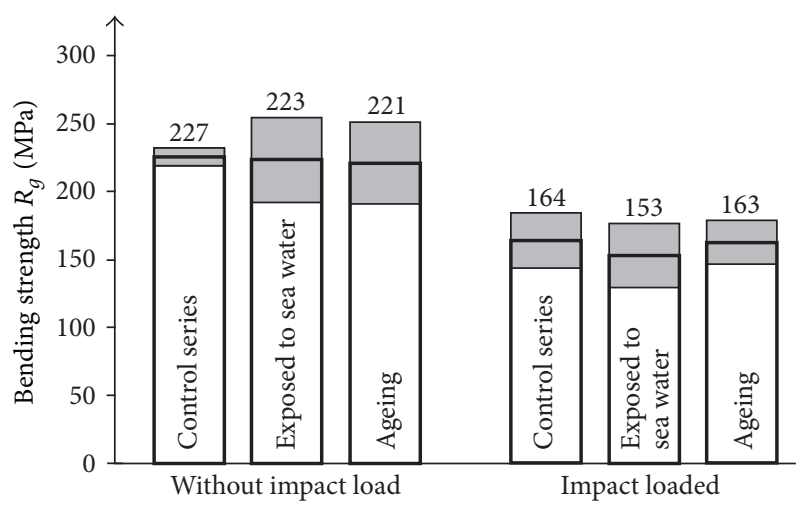

FIGURE 9: Comparison of the bending strength of GFRP.

samples for investigation (the remainder of $2 \times 10$ pieces). The samples underwent natural ageing in the conditions of the influence of the earth's atmosphere, during a period of 2,376 h (99 days). The designed laboratory stand corresponded to the real, changeable maintenance conditions of an aircraft.

\section{Results and Discussion}

The findings obtained in the bend tests were compared with the findings of the control series. Due to the method of manufacturing the composites, we adopted the level of confidence as 0.8 for the statistic analysis of the research findings. The analysis of the graphs shows that in the case of samples reinforced only with glass woven fabric (Figure 9) low energy impact loading decreases the bending strength for all research conditions by over $25 \%$ on average. For the samples which were not exposed to sea water, the decrease equals almost $28 \%$. For the samples which were exposed to sea water, the decrease equals $23 \%$. For the samples which were exposed to atmospheric ageing, the decrease equals $26 \%$. For all samples which underwent impact loading, the bending strength remained on a similar level, although detailed analysis is impossible due to a large range of the findings.

Figure 10 shows a graph which illustrates the influence of sea water upon the bending strength of samples which are reinforced with hybrids of fabrics layered interchangeably: glass fabric and carbon fabric. The bending strength of the composite exposed to the influence of sea water fell by almost

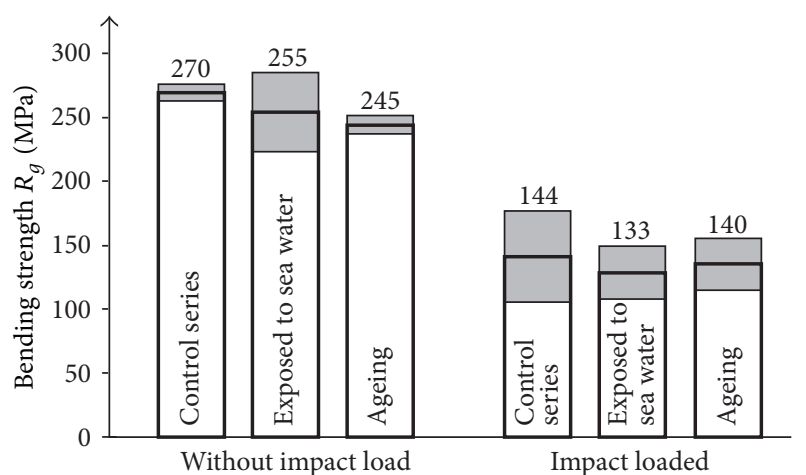

FIGURE 10: Comparison of flexural strength in composites with hybrid reinforcement.

$6 \%$, whereas in the case of the composite which underwent ageing it decreased by over $9 \%$. The strength of the composite underwent prior impact loading and then the influence of sea water fell by almost $8 \%$, and the one which underwent ageing fell by almost $3 \%$ in relation to the findings of the samples in the control series. Decrease in flexural strength of composites immersed in sea water may be (similar to that presented in [20]) associated with the degradation of the fibre/matrix interface, which changes the mechanism of fracture from matrix cracking to interfacial failure. In samples exposed to water (during ageing and during immersing in sea water) decrease of strength may be also an effect of bonded water which induces swelling, which in the presence of constraints (such as second-phase fibres) may leave important internal stresses [21, 22]. Moreover, long term exposure to moisture can also result in microcracking in the matrix, which may contribute to further mechanical property degradation and more water absorption beyond the usual equilibrium level of the undamaged matrix [23].

The comparison between the bending strength of glasscarbon samples which were not impact loaded and the samples which underwent prior impact loading showed a decrease in strength by $47 \%$ for the control group and $57 \%$ for the series which underwent tests on the influence of sea water and almost $43 \%$ for the samples which underwent atmospheric ageing.

One should note an extremely high decrease in bending strength of samples with hybrid reinforcement, which underwent impact loading. This results from poor strength of composites with carbon reinforcement to cross-impact loading. In case of such loads, carbon reinforcement is more prone to damage than glass reinforcements.

\section{Conclusions}

The conducted investigation proves the following:

(1) Natural atmospheric conditions exert a negative influence upon the bending strength of the glass-carbon polymer composite, which is not impact loaded. It is probably due to changes of temperature which degrade the interface between the two type of fibres and the matrix. 
(2) Use of a hybrid type of reinforcement leads to heightened flexural strength, by $19 \%$, in relation to the glass reinforcement. This is due to the use of two layers carbon fabrics instead of a glass fabric. Laminates reinforced with only carbon fibres or with hybrid (carbon/glass) reinforcement have bigger flexural strength than laminates reinforced solely with glass fibres [24-26]. This is because high modulus carbon fibres offer more resistance to flexural loading than low modulus glass fibres [25].

(3) Use of a carbon woven fabric significantly decreases bend strength of composite samples, which underwent prior low energy impact loading. This is connected with high sensitivity of carbon fibres to impact loading.

(4) Natural ageing and exposure to sea water have little influence on the bending strength of the glass fibre reinforced polymers.

(5) The interaction of the sea water influence with prior impact loading caused a total loss of strength in glass composites, by $33 \%$, and in glass-carbon composites by over $50 \%$.

(6) Natural ageing of samples which were exposed to previous impact loading caused a total decrease in strength by $28 \%$ for the composites with glass reinforcement and by as much as $48 \%$ for the composites with hybrid reinforcement.

(7) In the process of aircraft exploitation, it is necessary to pay attention to impact loaded damage of skin elements, which are made with laminates, particularly in case of low altitude flights over the sea. It is necessary to increase the frequency of inspections of the composite elements as well as introducing examination with nondestructive methods (e.g., thermal imaging ones) while performing maintenance.

(8) Apart from the reduction of bending strength, a loss of aesthetic values in samples was also observed, particularly those which were affected by sea water.

(9) It seems that the further stages of the research should focus on determining whether a huge fall in polymer composite strength with impact loaded damage, which is exposed to the influence of sea water, results mainly from the cracks in the matrix base, stress corrosion, or whether it stems from the affected internal structure of the material.

\section{Competing Interests}

The authors declare that they have no competing interests.

\section{References}

[1] A. Komorek and P. Przybylek, "Examination of the influence of cross-impact load on bend strength properties of composite materials, used in aviation," Maintenance and Reliability, vol. 14, no. 4, pp. 265-269, 2012.
[2] S. Ochelski, Metody Doświadczalne Mechaniki Kompozytów Konstrukcyjnych, WNT, Warszawa, Poland, 2004.

[3] A. Bełzowski, Z. Rechul, and J. Stasieńko, "Impact-related damage in glass roving reinforced laminate," Kompozyty (Composites), vol. 5, pp. 394-399, 2002.

[4] D. Kotnarowska, "Destruction of polymer coatings under the influence of operational factors," Logistyka, vol. 6, pp. 1775-1785, 2011.

[5] M. Rojek, "Methodology of diagnostic testing of polymeric matrix laminate composite materials," Open Access Library, vol. 2, pp. 1-148, 2011.

[6] A. Krzyżak and N. Szyszko, Deterioration, Dependability, Diagnostics, Edited by J. Stodola, J. Št’astný, D. Vališ, V. Neumann, University of Defence, Faculty of Military Technology, Department of Combat and Special Vehicles, Brno, Czech Republic, 2013.

[7] A. Krzyżak, J. Prażmo, and W. Kucharczyk, "Effect of natural ageing on the physical properties of polypropylene composites," Advanced Materials Research, vol. 1001, pp. 141-148, 2014.

[8] I. Ammar-Khodja, C. Picard, M. Fois, C. Marais, and P. Netchitaïlo, "Preliminary results on thermo-oxidative ageing of multihole carbon/epoxy composites," Composites Science and Technology, vol. 69, no. 9, pp. 1427-1431, 2009.

[9] W. D. Cook, M. Mehrabi, and G. H. Edward, "Ageing and yielding in model epoxy thermosets," Polymer, vol. 40, no. 5, pp. 1209-1218, 1999.

[10] B. Krywult, "The reasons for damage and deformation in fiberreinforced plastics," Polimery, vol. 47, no. 1, pp. 48-53, 2002.

[11] N.-H. Tai, M.-C. Yip, and C.-M. Tseng, "Influences of thermal cycling and low-energy impact on the fatigue behavior of carbon/PEEK laminates," Composites Part B: Engineering, vol. 30, no. 8, pp. 849-865, 1999.

[12] R. Nayak, D. P. Tarkes, and A. Satapathy, "A computational and experimental investigation on thermal conductivity of particle reinforced epoxy composites," Computational Materials Science, vol. 48, no. 3, pp. 576-581, 2010.

[13] S. A. Tanaeva, L. V. Bulgakova, L. S. Domorod, and L. E. Evseeva, "Effect of heat-aging on the thermal properties of glassreinforced epoxy plastic," Journal of Engineering Physics, vol. 29, no. 6, pp. 1538-1541, 1975.

[14] R. Chatys and A. Aniskevich, "Proces zniszczenia kompozytu polimerowego formowanego techniką worka próżniowego z uwzględnieniem wpływu wody i środowiska korozyjnego," in Polimery i Kompozyty Konstrukcyjne, G. Wróbel, Ed., pp. 71-78, Logos Press, Cieszyn, Poland, 2011.

[15] D. Kotnarowska, "Badanie erozji starzonych powłok epoksydowych," in Polimery I Kompozyty Konstrukcyjne 2010, G. Wróbel, Ed., pp. 165-173, Logos Press, Cieszyn, Poland, 2010.

[16] M. Wojtyniak, "Wpływ kwasu siarkowego na trwałość powłok polimerowych," in Polimery I Kompozyty Konstrukcyjne 2011, G. Wróbel, Ed., pp. 537-545, Logos Press, Cieszyn, Poland, 2011.

[17] M. K. Gupta and R. K. Srivastava, "A review on characterization of hybrid fibre reinforced polymer composite," American Journal of Polymer Science \& Engineering, vol. 4, pp. 1-7, 2016.

[18] W. Kucharczyk, A. Mazurkiewicz, and W. Żurowski, Nowoczesne materiały konstrukcyjne. Wybrane zagadnienia, Wydawnictwo Politechniki Radomskiej, Radom, 2010.

[19] M. Kozioł, "An effect of polymer matrix on mechanical performance of laminates reinforced with glass fibre Kompozyty (Composites)," Kompozyty, vol. 4, pp. 317-324, 2010. 
[20] T. S. Grant and W. L. Bradley, "In-situ observations in SEM of degradation of graphite/Epoxy composite materials due to seawater immersion," Journal of Composite Materials, vol. 29, no. 7, pp. 852-867, 1995.

[21] S. Alessi, G. Pitarresi, and G. Spadaro, "Effect of hydrothermal ageing on the thermal and delamination fracture behaviour of CFRP composites," Composites Part B: Engineering, vol. 67, pp. 145-153, 2014.

[22] G. M. Odegard and A. Bandyopadhyay, "Physical aging of epoxy polymers and their composites," Journal of Polymer Science, Part B: Polymer Physics, vol. 49, no. 24, pp. 1695-1716, 2011.

[23] M. Li, Temperature and Moisture Effects on Composite Materials for Wind Turbine Blades, Montana State University, Bozeman, Mont, USA, 2000.

[24] M. Kozioł, "The effect of reinforcing fabric type on mechanical performance of laminar FR epoxy composite," Composites Theory and Practice, vol. 1, pp. 60-65, 2012.

[25] R. Murugan, R. Ramesh, and K. Padmanabhan, "Investigation on static and dynamic mechanical properties of epoxy based woven fabric glass/carbon hybrid composite laminates," Procedia Engineering, vol. 97, pp. 459-468, 2014.

[26] J. Zhang, K. Chaisombat, S. He, and C. H. Wang, "Hybrid composite laminates reinforced with glass/carbon woven fabrics for lightweight load bearing structures," Materials \& Design, vol. 36, pp. 75-80, 2012. 

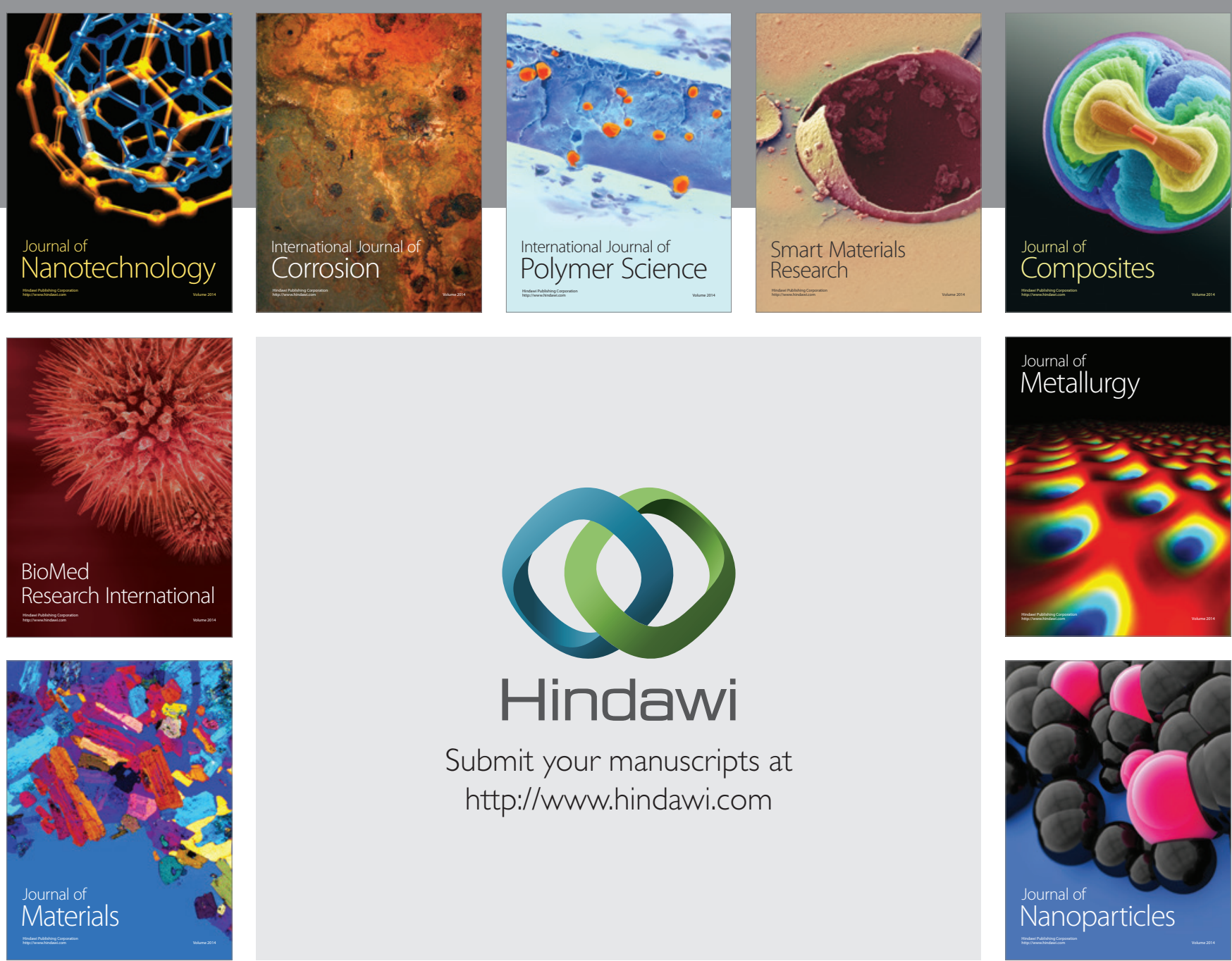

\section{Hindawi}

Submit your manuscripts at

http://www.hindawi.com

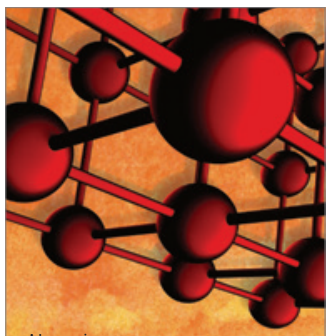

Materials Science and Engineering
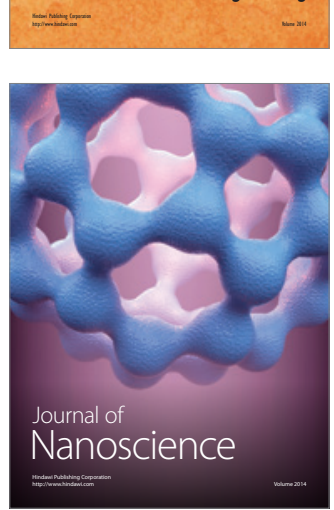
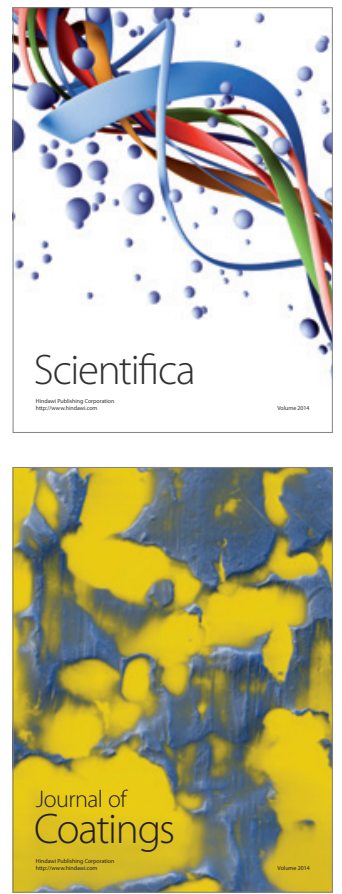
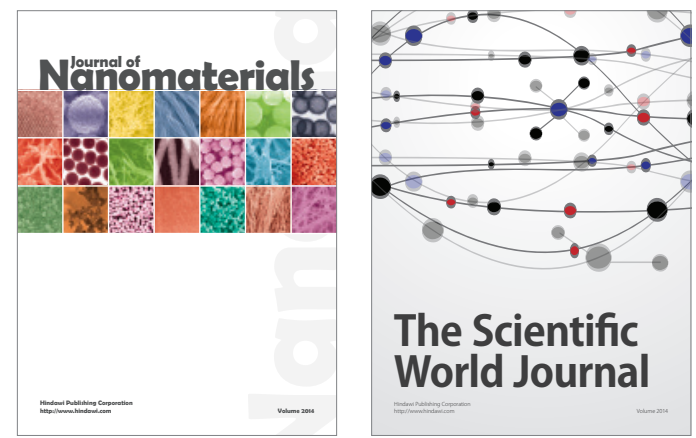

The Scientific World Journal
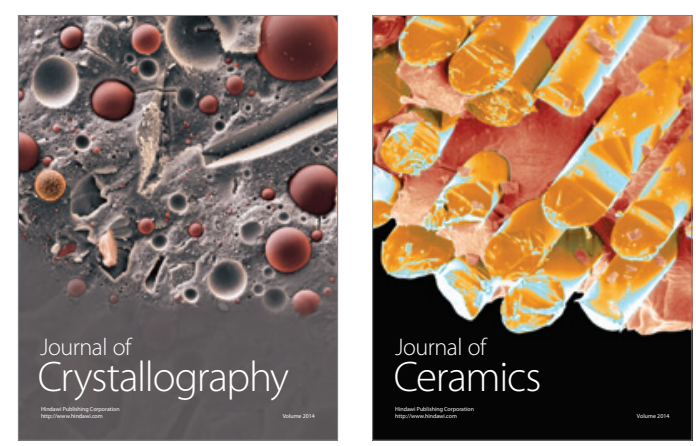
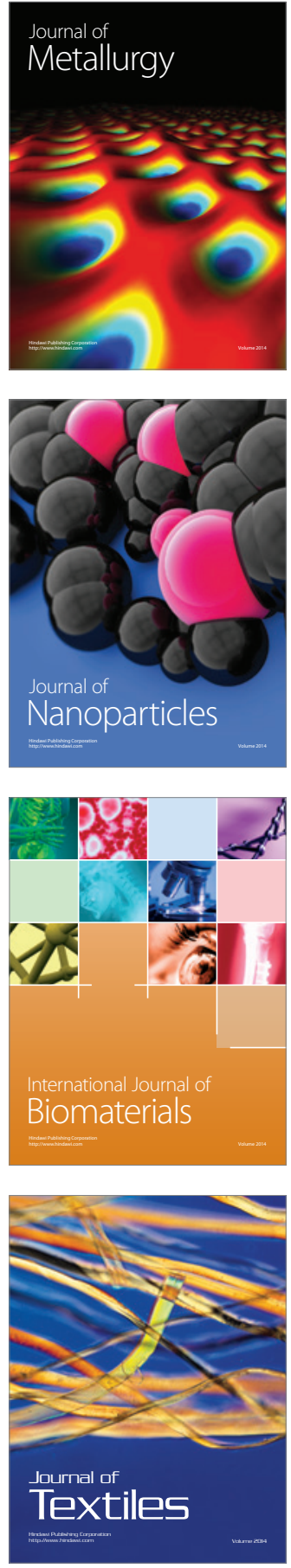